\title{
Inspeksi Material menggunakan Mikro-Radiografi Sinar-X Digital melalui Pengukuran Densitas
}

\author{
Prasetyo Listiaji*1 dan Gede Bayu Suparta ${ }^{2}$ \\ ${ }^{1}$ Jurusan IPA Terpadu, Fakultas Matematika dan Ilmu Pengetahuan Alam, Universitas Negeri Semarang \\ Sekarang, Gunungpati, Semarang, Jawa Tengah, 50229 \\ ${ }^{2}$ Jurusan Fisika, Fakultas Matematika dan Ilmu Pengetahuan Alam, Universitas Gadjah Mada \\ Sekip Utara, Bulaksumur, Yogyakarta 55281
}

Intisari

\begin{abstract}
Radiografi sinar-X digital adalah teknik pencitraan digital non-destruktif dengan memanfaatkan radiasi sinar-X yang menembus objek material. Teknik ini dapat digunakan untuk menganalisis struktur internal dan komposisi objek dengan baik. Telah dilakukan penelitian mengenai inspeksi material menggunakan mikro-radiografi sinar$\mathrm{X}$ digital yang telah dikembangkan di Departemen Fisika FMIPA UGM. Sampel material yang di inspeksi adalah pensil HB dan 2B. Semua sampel diradiasi sinar-X dengan tegangan tabung $30 \mathrm{kV}$ dan arus filamen 20 $\mathrm{mA}$. Beberapa citra diambil untuk setiap sampel, kemudian dilakukan rata-rata dan dihitung nilai skala abuabu (intensitas). Densitas dihitung berdasarkan variasi perbedaan intensitas yang melewati pensil. Hasil citra radiografi menunjukkan bahwa bagian struktur internal objek pensil yaitu kayu dan grafit dapat dibedakan. Hasil pengukuran diperoleh densitas grafit pensil HB sebesar $(2,52 \pm 0,012) \mathrm{g} / \mathrm{cm}^{3}$ dan densitas grafit pensil 2B sebesar $(1,84 \pm 0,02) \mathrm{g} / \mathrm{cm}^{3}$. Hasil nilai densitas grafit HB dan grafit $2 \mathrm{~B}$ yang berbeda menunjukkan bahwa teknik radiografi sinar-X dapat menjadi alternatif untuk keperluan inspeksi material dan pengukuran densitas.
\end{abstract}

\begin{abstract}
$\mathrm{X}$-ray digital radiography is a non-destructive digital imaging technique that utilizes X-ray radiation that penetrates material objects. This technique can be used to analyze the internal structure and composition of objects properly. Research has been carried out on material inspection using X-ray digital micro-radiography that has been developed in the Physics Department, FMIPA UGM. Material samples inspected were2B and HB pencils. All samples were irradiated by X-rays with a tube voltage of $30 \mathrm{kV}$ and a filament current of $20 \mathrm{~mA}$. Several images were taken for each sample, then averaged and calculated the grayscale value (intensity). Density was calculated based on variations in the intensity difference that passes through the pencil. The radiographic image showed that the internal structure of the pencil object, were wood and graphite can be distinguished. The measurement results were obtained for HB pencils, the value of the graphite density of HB pencils was $(2.52$ $\pm 0.02) \mathrm{g} / \mathrm{cm}^{3}$ and graphite density of $2 \mathrm{~B}$ pencils was $(1.84 \pm 0.02) \mathrm{g} / \mathrm{cm}^{3}$. The results of the density difference between HBgraphiteand 2B graphite indicate that X-ray radiography techniques can be an alternative for material inspection purposes and density measurement.
\end{abstract}

Keywords: density; digital radiography; material inspection; x-ray imaging.

*Corresponding author: p.listiaji@mail.unnes.ac.id

http://dx.doi.org/10.12962/j24604682.v16i1.4817

2460-4682 @DDepartemen Fisika, FSAD-ITS

\section{PENDAHULUAN}

Penggunaan teknologi nuklir pada bidang industri telah berkembang sangat pesat, salah satunya dalam metode uji tak rusak atau Nondestructive Testing (NDT). NDT merupakan teknik non-invasif untuk menentukan keutuhan bahan, komponen atau struktur atau secara kuantitatif mengukur karakteristik suatu objek [1]. Salah satu teknologi NDT yang dapat digunakan adalah radiografi sinar-X dengan memanfaatkan radiasi sinar-X yang menembus suatu objek. Radiografi memberikan citra dua dimensi (2D) sebagai proyeksi dari objek tiga dimensi (3D) dari sudut pandang tertentu [2]. Teknik ini memanfaatkan perubahan intensitas sinar-X yang ditransmisikan setelah menembus objek yang dideteksi [3].

Sistem radiografi saat ini terus mengalami perkembangan dari sistem radiografi yang berbasis film menjadi sistem radiografi digital. Keduanya berbeda karena perbedaan pada unit detektor pendeteksi sinar-X yang digunakan [4]. Radiografi konvensional memanfaatkan film sebagai unit pendeteksi, sedangkan radiografi digital memanfaatkan detektor yang dapat menghasilkan citra digital [5]. Sistem radiografi digital umumnya memanfaatkan $X$-ray fluoroscopy image converter yang terdiri dari sebuah layar fluoresens pada ruang gelap yang dipasangkan dengan kamera sebagai detek- 


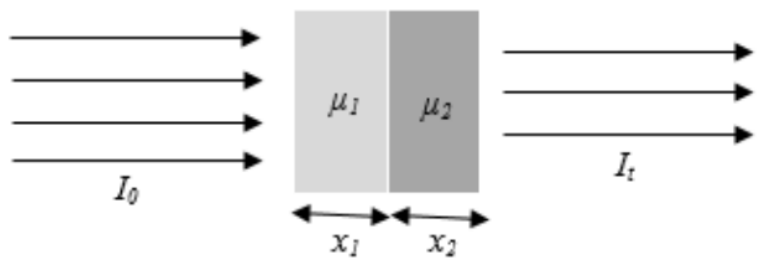

Gambar 1: Skema paparan sinar-X menembus material dengan dua jenis bahan yang berbeda.

tor beserta perlengkapan digitisasi [6]. Penggunaan kamera sebagai detector akan menghasilkan data berupa citra digital yang menggambarkan nilai distribusi intensitas cahaya yang dinyatakan dalam skala keabuaan (grayscale) [7].

Suatu sistem mikro-radiografi sinar-X digital telah dikembangkan oleh Departemen Fisika, Universitas Gadjah Mada untuk keperluan inspeksi material. Beberapa penelitian telah dilakukan menggunakan sistem diantaranya pengukuran koefisien mulai termal kabel [1], pengukuran densitas plastik dan akrilik [5], pengukuran koefisien atenuasi linear [8], inspeksi kualitas kapasitor elektrolit dan pensil [9, 10].

Ketika sinar-X mengenai suatu material, maka akan menggalami penurunan intensitas radiasi akibat dari interaksi foton sinar-X dengan atom atau molekul material tersebut. Hubungan antara intensitas datang $\left(\mathrm{I}_{\circ}\right)$, intensitas transmisi $\left(\mathrm{I}_{t}\right)$, dan tebal material $(\mathrm{x})$ dinyatakan dengan persamaan LambertBeer [11]

$$
\begin{aligned}
I_{t} & =I_{\circ} e^{-\mu x} \\
\ln \left(\frac{I_{\circ}}{I_{t}}\right) & =\mu x
\end{aligned}
$$

dengan $\mu$ adalah koefisien atenuasi linier material.

Jika suatu material terdiri dari dua jenis material yang berbeda (Gambar 1) yang memiliki koefisien atenuasi linear $\mu_{1}$ dan $\mu_{2}$ serta ketebalan $\mathrm{x}_{1}$ dan $\mathrm{x}_{2}$, maka paparan sinar-X yang mengenai material tersebut akan memenuhi Pers.(3).

$$
I_{t}=I_{\circ} e^{-\left(\mu_{1} x_{1}+\mu_{2} x_{2}\right)}
$$

Pers.(3) kemudian dapat dimodifikasi menjadi Pers.(4).

$$
\ln \left(\frac{I_{\circ}}{I_{t}}\right)=\mu_{1} x_{1}+\mu_{2} x_{2}
$$

Pada penelitian ini suatu citra radiografi obyek pensildari bahan kayu dan grafit diperoleh sehingga nilai $\mathrm{I}_{\circ}$ merupakan nilai grayscale background, sedangkan $\mathrm{I}_{t}$ adalah nilai grayscale citra pada obyek.

Koefisien atenuasi massa atau koefisien serapan massa didefiniskan sebagai koefisien serapan pada suatu ketebalan 1 gram bahan dengan luas permukaan $1 \mathrm{~cm}^{2}$ [5]. Satuan dari koefisien atenuasi massa yaitu $\mathrm{cm}^{2} / \mathrm{g}$. Koefisien atenu-

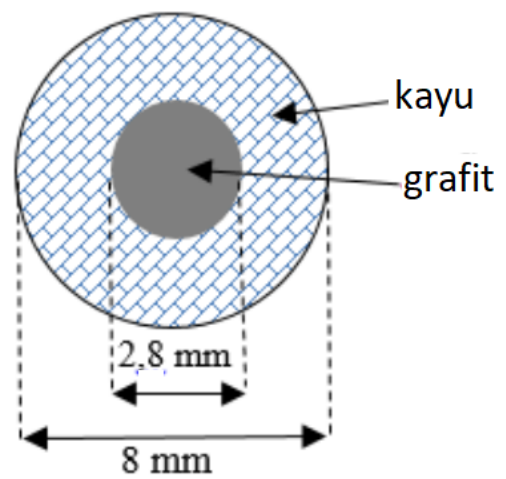

Gambar 2: Ilustrasi model material pensil yang digunakan dalam penelitian.

asi massa dihitung secara tidak langsung dengan Pers.(5).

$$
\begin{aligned}
& \ln \left(\frac{I_{\circ}}{I_{t}}\right)=\mu_{1} x_{1}+\mu_{2} x_{2} \\
& \ln \left(\frac{I_{\circ}}{I_{t}}\right)=\frac{\mu_{1}}{\rho_{1}} x_{1} \rho_{1}+\frac{\mu_{2}}{\rho_{2}} x_{2} \rho_{2} \\
& \ln \left(\frac{I_{\circ}}{I_{t}}\right)=\mu_{m 1} x_{1} \rho_{1}+\mu_{m 2} x_{2} \rho_{2}
\end{aligned}
$$

Pers.(5) menunjukkan koefisien atenuasi massa sebesar $\mu_{m}=\frac{\mu}{\rho}$ dengan $\rho$ adalah densitas material. Pada penelitian ini diajukan metode inspeksi material menggunakan mikroradiografi digital melalui pengamatan visual citra radiografi dan pengukuran densitas secara tak merusak. Densitas merupakan karakteristik penting untuk mengetahui kepadatan sebuah material. Dengan mengetahui densitas maka dapat digunakan sebagai salah satu acuan kualitas material tersebut.

\section{METODOLOGI}

Sampel material yang diinspeksi adalah dua jenis pensil yaitu HB dan 2B dengan bentuk penampang lingkaran. Ukuran diameter pensil sebesar $8 \mathrm{~mm}$ dan diameter grafitnya sebesar 2,8 mm. Pada penelitian ini digunakan 6 buah pensil untuk masing-masing jenis.

Peralatan yang digunakan pada penelitian ini yaitu mikroradiografi sinar-X digital yang telah dikembangkan oleh Jurusan Fisika FMIPA UGM [10]. Susunan peralatan penelitian ditunjukkan pada Gambar 3. Adapun peralatan terdiri dari generator sinar- $X$ dengan target anode molibdenium (Mo) sebagai pembangkit sinar-X, pemegang sampel, dudukan sampel dan detektor sinar-X fluoresensi yang dirangkai dengan kamera CMOS. Kamera CMOS dikendalikan oleh perangkat lunak khusus yang dikembangkan untuk akuisisi citra radiograf. Pengolahan citra menggunakan platform Image-J.

Proses pengambilan data menggunakan generator sinar- $\mathrm{X}$ dengan tegangan anode-katode $30 \mathrm{kV}$ dan arus filamen 20 $\mathrm{mA}$. Dalam sekali pemaparan, sistem dapat merekam 5 

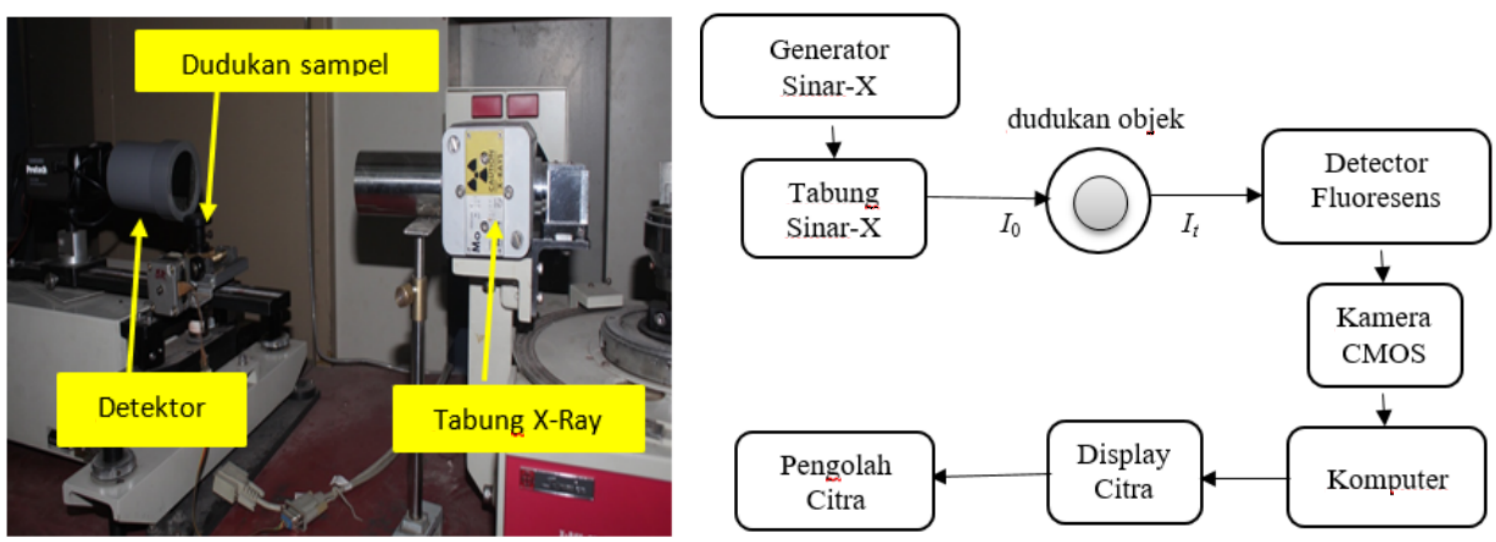

Gambar 3: Susunan instrumen dan skema mikro-radiografi sinar-X digital.

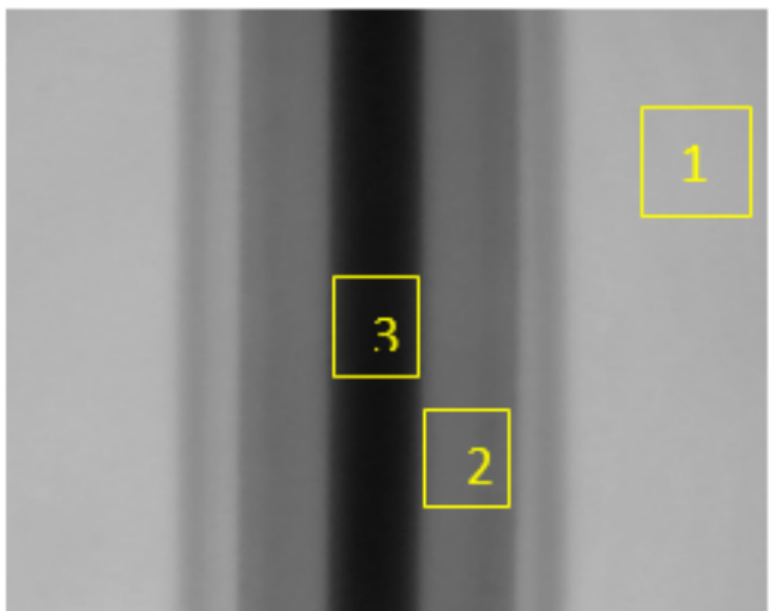

Gambar 4: Contoh citra radiografi objek pensil.

citra radiografi sekaligus. Setelah diperoleh 5 citra untuk masing-masing sampel kemudian dirata-rata menggunakan Image-J. Dari citra radiografi digital tersebut diharapkan dapat dilihat secara visual struktur internal material yang diinspeksi (Gambar 4). Citra radiograf juga dianalisis profil garisnya untuk melihat profil intensitas transmisi sinar-X.

Berdasarkan Gambar 4, nilai $\mathrm{I}_{\circ}$ dapat diukur melalui ratarata grayscale pada Region of Interest (ROI) daerah 1 dan nilai $\mathrm{I}_{t}$ diukur melalui grayscale $\mathrm{ROI}$ daerah 2 dan 3 . Ukuran ROI yang digunakan adalah $(10 \times 10)$ piksel. Bisa diamati ROI daerah 2 adalah intensitas sinar-X setelah melalui material kayu sehingga informasi intensitas yang diperoleh digunakan untuk menghitung densitas kayu. Sedangkan ROI daerah 3 adalah intensitas sinar-X setelah melalui material kayu dan grafit kemudian informasi intensitas yang diperoleh digunakan untuk menghitung densitas grafit mengacu Pers.(5) menggunakan Microsoft Excel. Karena ROI untuk menghitung intensitas transmisi diusahakan sebisa mungkin terletak pada pusat pensil sehingga sinar- $X$ akan melewati kayu setebal 5,2 mm dan grafit setebal 2,8 mm (lihat Gambar 2). Secara garis besar langkah penelitian ditunjukkan pada Gambar 5 .

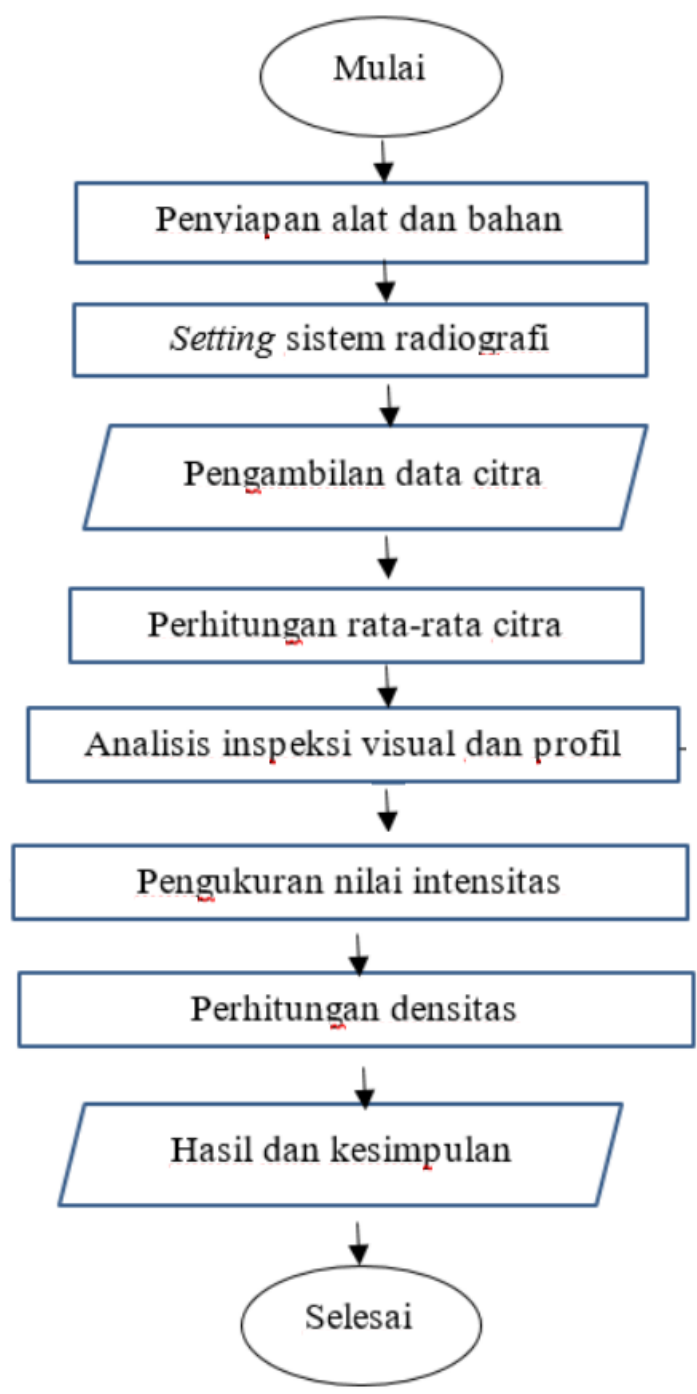

Gambar 5: Tahapan penelitian. 


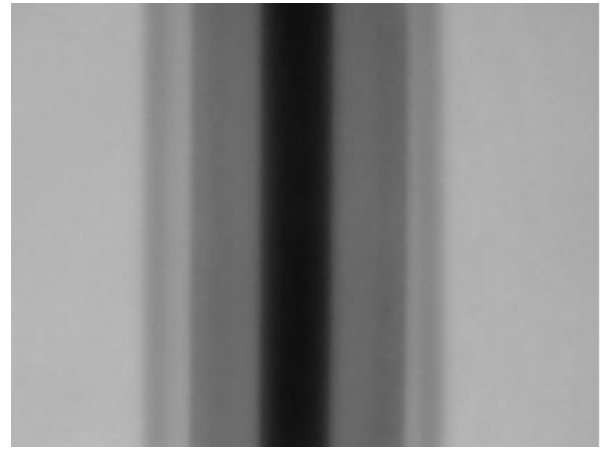

(a) Pensil HB

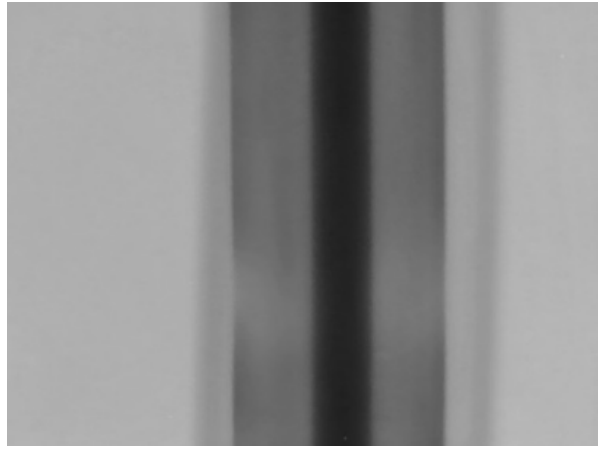

(b) Pensil 2B

Gambar 6: Citra Radiografi objek pensil.

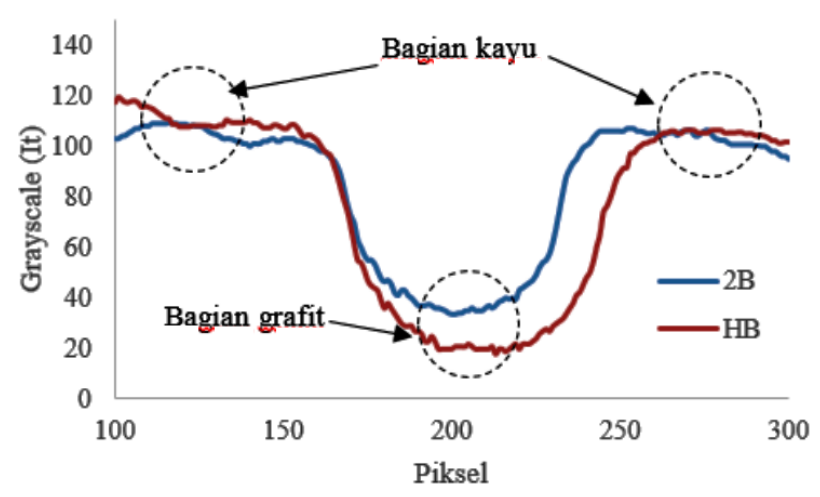

Gambar 7: Grafik profil intensitas transmisi sinar-X pada citra pensil untuk bagian kayu dan grafit.

\section{HASIL DAN DISKUSI}

Pada penelitian ini diperoleh citra hasil radiografi material pensil yang ditunjukkan oleh Gambar 6. Setelah dilakukan pemotongan diperoleh citra dengan ukuran $(630 \times 500)$ piksel.

Citra radiografi telah dapat membedakan struktur internal pensil, batas luar menunjukkan batas tabung tempat sampel, bagian yang lebih dalam menunjukkan batas struktur kayu, dan bagian terdalam menunjukkan batas struktur grafit. Jika diamati secara visual grafit pensil HB terlihat lebih gelap dibandingkan grafit pensil $2 \mathrm{~B}$, hal ini menunjukkan intensitas sinar-X yang berhasil menembus grafit HB lebih kecil dibandingkan grafit $2 \mathrm{~B}$ atau dapat diasumsikan densitas grafit HB lebih besar daripada grafit 2B. Untuk mengukur seberapa perbedaan intensitas sinar-X yang dapat menembus grafit HB dan 2B di lakukan analisis profil garis seperti yang ditunjukkan oleh grafik pada Gambar 7.

Berdasarkan analisis profil garis pada Gambar 7 dapat diperoleh hasil bahwa terdapat perbedaan nilai grayscale yang cukup jelas pada grafit $\mathrm{HB}$ dan 2B. Pada bagian kayu dari kedua pensil nilai grayscale-nya relatif sama me-
TABEL I: Pengukuran intensitas terusan dan perhitungan densitas grafit.

\begin{tabular}{cccc}
\hline \hline Sampel & $\mathrm{I}_{\circ}$ & $\mathrm{I}_{t}$ grafit $\rho$ grafit $\left(\mathrm{g} / \mathrm{cm}^{3}\right)$ \\
\hline HB 1 & $175 \pm 2$ & $21 \pm 1$ & $2,45 \pm 0,02$ \\
HB 2 & $174 \pm 2$ & $21 \pm 2$ & $2,44 \pm 0,02$ \\
HB 3 & $175 \pm 2$ & $20 \pm 1$ & $2,51 \pm 0,02$ \\
HB 4 & $176 \pm 3$ & $19 \pm 1$ & $2,58 \pm 0,03$ \\
HB 5 & $175 \pm 2$ & $20 \pm 1$ & $2,51 \pm 0,03$ \\
HB 6 & $174 \pm 2$ & $18 \pm 1$ & $2,63 \pm 0,03$ \\
2B 1 & $173 \pm 2$ & $33 \pm 1$ & $1,87 \pm 0,02$ \\
2B 2 & $174 \pm 2$ & $34 \pm 1$ & $1,84 \pm 0,02$ \\
2B 3 & $174 \pm 2$ & $38 \pm 2$ & $1,70 \pm 0,02$ \\
2B 4 & $174 \pm 2$ & $33 \pm 1$ & $1,88 \pm 0,02$ \\
2B 5 & $175 \pm 2$ & $34 \pm 2$ & $1,85 \pm 0,02$ \\
2B 6 & $175 \pm 2$ & $33 \pm 1$ & $1,89 \pm 0,02$ \\
\hline \hline
\end{tabular}

nunjukan hasil konsisten untuk citra jenis material yang sama.

Koefisien atenuasi massa dari grafit diperoleh berdasarkan database NISTIR 5632 dari NIST (physical meas Laboratory) dengan nilai $0,8071 \mathrm{~cm}^{2} / \mathrm{g}$ [11]. Perhitungan secara estimasi energi foton pada pesawat sinar-X yang digunakan adalah $15,77 \mathrm{KeV}$ untuk tegangan tabung $30 \mathrm{kV}$ [5]. Kayu yang umum digunakan pada pensil adalah jenis sengon (albizia) dengan densitas sebesar $0,40 \mathrm{~g} / \mathrm{cm}^{3}$ dan koefisien atenuasi massa sebesar $0,681 \mathrm{~cm}^{2} / \mathrm{g}$ [12]. Mengacu pada Pers.(5) diperoleh hasil pengukuran intensitas transmisi dan perhitungan densitas grafit yang disajikan dalam Tabel I.

Berdasarkan Tabel I diperoleh hasil densitas rata-rata grafit pensil HB sebesar $(2,52 \pm 0,02) \mathrm{g} / \mathrm{cm}^{3}$ dan densitas rata-rata grafit pensil $2 \mathrm{~B}$ sebesar $(1,84 \pm 0,02) \mathrm{g} / \mathrm{cm}^{3}$. Hasil ini menunjukkan terdapat perbedaan densitas antara grafit $\mathrm{HB}$ dan $2 \mathrm{~B}$. Grafit HB memiliki kerapatan yang lebih tinggi dibandingkan grafit HB. Densitas grafit standar dalam bentuk padat adalah $2.3-2.7 \mathrm{~g} / \mathrm{cm}^{3}$ [13]. Jika dibandingkan dengan hasil perhitungan maka untuk densitas grafit HB sesuai rentang dalam densitas grafit standar sedangkan densitas grafit 2B menunjukan nilai lebih kecil. Densitas material mempengaruhi besar inten- 
sitas radiasi Sinar-X yang mampu menembus material. Bisa diamati pada Tabel I, intensitas transmisi sinar-X yang menembus grafit HB lebih kecil dibandingkan dengan intensitas transmisi sinar-X yang menembus grafit $2 \mathrm{~B}$.

\section{SIMPULAN}

Berdasarkan hasil penelitian ini disimpulkan bahwa mikroradiografi sinar-X digital dengan energi sinar-X $30 \mathrm{kV}, 20 \mathrm{~mA}$ dapat digunakan untuk menginpeksi struktur internal material pensil. Setiap bagian dari struktur internal dapat dibedakan secara visual dan batas-batas yang terlihat jelas. Citra radiografi yang dihasilkan juga menunjukkan grayscale yang berbeda antara setiap bagian dari struktur internal. Hasil penelitian menunjukan grafit pensil HB memiliki densitas sebesar $(2,52$ $\pm 0,02) \mathrm{g} / \mathrm{cm}^{3}$ dan grafit pensil $2 \mathrm{~B}$ memiliki densitas sebesar $(1,84 \pm 0,02) \mathrm{g} / \mathrm{cm}^{3}$. Jadi, teknik ini dapat digunakan sebagai metode alternatif tidak merusak untuk menghitung densitas material.

\section{Ucapan Terima Kasih}

Ucapan terima kasih diberikan Grup Riset Fisika Citra, Departemen Fisika, FMIPA, UGM yang telah membantu.
[1] Y. Affriyenni, "Pengukuran Koefisien Muai Termal pada Kabel Listrik Menggunakan Mikroradiografi Sinar-X Digital”, Thesis, Universitas Gadjah Mada, 2017

[2] G.B. Suparta, A.C. Louk, H. Kurniasari, dan G.A. Wiguna, "The Use of X-Ray Micro-Digital Radiography for Clay Material Inspection”, Proceedings of SPIE, 9234, 2014.

[3] J. Dudak, et al., "X-ray micro-CT scanner for small animal imaging based on Timepix detector technology", Nucl. Instruments Methods Phys. Res. Sect. A Accel. Spectrometers, Detect. Assoc. Equip., vol. 773, pp. 81-86, 2015.

[4] Susilo, Sunarmo, I.K. Swakarma, R. Setiawan, and E. Wibowo, "Kajian Sistem Radiografi Digital sebagai Pengganti Sistem Computed Radiography yang Mahal", J. Fis. Indones., vol. 17, no. 50, pp. 4-43, 2013.

[5] G.A. Wiguna, et al., "Penentuan Densitas Akrilik dan Plastik berdasarkan Citra Radiografi Digital", Jurnal Fisika dan Aplikasinya, vol. 15, no. 1, pp. 12-16, 2018.

[6] G.B. Suparta, A.C. Louk, N.H. Sam, dan G.A. Wiguna, "Quality Performance of Customized and Low Cost X-Ray MicroDigital Radiography System", Proceedings of SPIE, 9234, 2014.

[7] P. Listiaji, "Metode Pencitraan Spektroskopi Cahaya Tampak untuk Pengujian Konsentrasi Gula Dalam Larutan”, PhD Thesis, Universitas Gadjah Mada, 2018.
[8] Mousa, Almahdi, K. Kusminarto, and G.B. Suparta, "A New Simple Method to Measure the X-ray Linear Attenuation Coefficients of Materials using Micro-Digital Radiography Machine", International Journal of Applied Engineering Research vol. 12, no. 21, pp. 10589-10594, 2017.

[9] I.G.B.P. Pratama, and G.B. Suparta, "Quality inspection on electrolytic capacitors using micro-computed tomography", International Conference on Experimental Mechanics 2014, vol. 9302, International Society for Optics and Photonics, 2015.

[10] P. Listiaji, et al., "Quality inspection on internal structures of pencils using X-Ray micro-computed tomography", Proceeding of ICMSE4.1, pp 165-170, 2017.

[11] J.H. Hubbell, "Review of photon interaction cross section data in the medical and biological context", Phys. Med. Biol., vol. 44, no. 1, R1-22, 1999.

[12] S. Aggrey-Smith, et al., "Study of Radiation Shielding Properties of selected Tropical Wood Species for X-rays in the 50-150 keV Range", The Open Access Journal of Science and Technology, vol. 4, 2016.

[13] Engineering Tool Box, "Densities of Solids", 2009, [online] Tersedia di: https://www.engineeringtoolbox.com/densitysolids - d-1265.html [Diakses pada30 Mei 2019]. 